\title{
No differences in in vivo kinematics between six different types of knee prostheses
}

\author{
N. Wolterbeek • R. G. H. H. Nelissen • \\ E. R. Valstar
}

Received: 15 December 2010/ Accepted: 1 July 2011 / Published online: 15 July 2011

(C) The Author(s) 2011. This article is published with open access at Springerlink.com

\begin{abstract}
Purpose The aim of this study was to compare a broad range of total knee prostheses with different design parameters to determine whether in vivo kinematics was consistently related to design. The hypothesis was that there are no clear recognizable differences in in vivo kinematics between different design parameters or prostheses.

Methods At two sites, data were collected by a single observer on 52 knees (49 subjects with rheumatoid arthritis or osteoarthritis). Six different total knee prostheses were used: multi-radius, single-radius, fixed-bearing, mobilebearing, posterior-stabilized, cruciate retaining and cruciate sacrificing. Knee kinematics was recorded using fluoroscopy as the patients performed a step-up motion.

Results There was a significant effect of prosthetic design on all outcome parameters; however, post hoc tests showed that the NexGen group was responsible for $80 \%$ of the significant values. The range of knee flexion was much smaller in this group, resulting in smaller anterior-posterior translations and rotations.

Conclusion Despite kinematics being generally consistent with the kinematics intended by their design, there were no clear recognizable differences in in vivo kinematics between different design parameters or prostheses.
\end{abstract}

\footnotetext{
N. Wolterbeek ( $\square)$ · R. G. H. H. Nelissen · E. R. Valstar Biomechanics and Imaging Group, Department of Orthopaedics, Leiden University Medical Center, PO Box 9600,

J11-S, 2300 RC Leiden, The Netherlands

e-mail: N.Wolterbeek@lumc.nl

E. R. Valstar

Department of Biomechanical Engineering,

Faculty of Mechanical, Maritime and Materials Engineering,

Delft University of Technology, Mekelweg 2,

2628 CD Delft, The Netherlands
}

Hence, the differences in design parameters or prostheses are not distinct enough to have an effect on clinical outcome of patients.

Level of evidence Therapeutic study, Level III.

Keywords Kinematics · Fluoroscopy $\cdot$ Single-radius · Multi-radius $\cdot$ Mobile-bearing $\cdot$ Fixed-bearing

\section{Introduction}

Many studies have characterized the in vivo motions of total knee prostheses. Major conclusions are that there is a broad range of kinematics and that specific prostheses have specific advantages and disadvantages [2, 5, 27]. For example, posterior-stabilized knee prostheses were developed to prevent reversed anterior translations of the femoral condyles during flexion seen in cruciate sacrificing prostheses. The induced posterior displacement will avoid impingement and thereby improve the range of motion of the knee [16]. However, it is no exception that the actual in vivo kinematics of knee prostheses is not in line with the desired kinematics as intended by the design. Understanding the effect of design choices on in vivo kinematics, stability and muscle activation has become more important because of the increasingly clear connection between knee prosthesis kinematics and clinical performance. Therefore, the aim of this study was to compare a broad range of total knee prostheses with different design parameters (multiradius, single-radius, fixed-bearing, mobile-bearing, posterior-stabilized, cruciate retaining and cruciate sacrificing) to determine whether in vivo kinematics was consistently related to design. The hypothesis was that there are no clear recognizable differences in in vivo kinematics between different design parameters or prostheses. 


\section{Materials and methods}

At two sites, data were collected by a single observer on 52 knees (49 subjects with rheumatoid arthritis or osteoarthritis). Six different total knee prostheses were used (Table 1). Total knee replacements were performed by five surgeons at three hospitals in two countries (the Netherlands and United Kingdom). All surgeons were specialized in total knee arthroplasty, and prostheses were implanted according to the operative techniques described by the manufacturer. Based on a previous fluoroscopy study, relative motions of $0.3^{\circ}$ could be detected when ten patients were included in each group [13]. Knee kinematics was recorded using fluoroscopy as the patients performed a step-up motion. The experimental set-up was the same for all patients. Patients' reported functional ability (knee score and function score) was quantified pre- and postoperatively for the prospective patients using the Knee Society Score (KSS) [11]. The study was approved by the respective local medical ethics committees, and all patients gave informed consent.

\section{Fluoroscopy}

The patients were asked to perform a step-up motion (height $18 \mathrm{~cm}$ ) with bare feet in front of a flat panel fluoroscope (15 frames/sec, resolution $1,024 \times 1,024$, pulse width $<3.2 \mathrm{~ms})$. Patients were instructed to keep their weight onto the leg of interest and to perform the motions in a controlled manner. Three-dimensional (3D) models (reverse engineered or computer aided design) of the tibial and femoral components were used to assess the position and orientation of the components in the fluoroscopic images [17]. In case of a mobile-bearing prosthesis, during surgery $1 \mathrm{~mm}$ tantalum markers were inserted in predefined non-weight bearing areas of the mobile insert to visualize the polyethylene. Roentgen stereophotogrammetric analysis (RSA) was used to create accurate 3D models of the markers of the inserts to assess position and orientation of the mobile insert in the fluoroscopic images. This technique showed to have an axial rotation accuracy of $0.1^{\circ}$ and $0.1 \mathrm{~mm}$ [17]. The coordinate system was defined as the local coordinate system of the tibial component. At maximal extension, the axial rotation is defined as zero. The minimal distance between the femoral condyles and the tibial base plate was calculated independently for the medial and lateral condyle and projected on the tibial plane to show the anterior-posterior motions. This line was projected onto the transverse plane of the tibial plateau for each fluoroscopic frame. All images were processed using a commercially available software package (Model-based RSA, Medis specials b.v., Leiden, The Netherlands).
Statistical analysis

A chi-square test (Cramer's V) was used to test whether the prosthesis groups were different on variables, such as age, gender, BMI and functional and knee scores. An ANOVA was used to test for differences in outcome variables among the prosthetic groups. Levene's test was used to test for homogeneity of variances between prosthetic groups. For femoral axial rotation $(P=0.006)$ and insert axial rotation $(P=0.001)$, the variances were not equal. To correct for this unequal variance and to correct for the different group sizes, Brown-Forsythe correction was used. When a significant effect of prosthetic design on an outcome variable was found, post hoc tests were performed to test which groups were different.

\section{Results}

Age at surgery, BMI, pre-operative KSS knee score and function score did not differ significantly between groups (Table 1). The PFC-Sigma patients had no pre- or postoperative scores. The Duracon patients were included retrospectively. Therefore, no pre-operative clinical scores were available. There was no difference in post-operative KSS function score between groups. However, there was a small significant difference in post-operative KSS knee score $(P=0.045)$. Post-operatively, the Duracon patients (multi-radius fixed-bearing cruciate retaining) scored highest on both KSS function score and knee score. In all groups, the KSS function score and knee score increased post-operatively. All patients were considered clinically successful without significant pain or measurable ligamentous instability. Also, no clinical deviations were reported, such as extension lags or flexion contractures.

Knee flexion angle

The NexGen group had significant smaller knee flexion angles compared to the other prosthetic groups (Triathlon MB $P=0.005$; Triathlon FB $P=0.004$; Duracon $P=0.003$; ROCC $P=0.007$; PFC-Sigma $P=0.017$ ). There were no significant differences between the other groups (Table 2).

\section{Axial rotation}

The NexGen group had significantly smaller femoral axial rotation compared to the Duracon group $(P=0.000)$, the Triathlon MB group $(P=0.024)$ and Triathlon FB group $(P=0.001)$. There were no differences in axial femoral rotation between the rest of the groups. The mean range of axial rotation of the insert of the NexGen patients was also 
Table 1 Overview of the prostheses used, congruency of the insert and number of knees and patient characteristics (mean and standard deviation)

\begin{tabular}{|c|c|c|c|c|c|c|c|c|c|c|}
\hline \multirow[t]{2}{*}{ Prosthesis } & \multirow{2}{*}{$\begin{array}{l}\text { Design } \\
\text { parameters }\end{array}$} & \multirow{2}{*}{$\begin{array}{l}\text { Number } \\
\text { of knees }\end{array}$} & \multirow{2}{*}{$\begin{array}{l}\text { Follow-up } \\
\text { (months) }\end{array}$} & \multirow{2}{*}{$\begin{array}{l}\text { Male/ } \\
\text { female }\end{array}$} & \multirow{2}{*}{$\begin{array}{l}\text { Age } \\
\text { (years) }\end{array}$} & \multirow{2}{*}{$\begin{array}{l}\text { BMI } \\
\left(\mathrm{kg} / \mathrm{m}^{2}\right)\end{array}$} & \multicolumn{2}{|c|}{ Pre-operative } & \multicolumn{2}{|c|}{ Post-operative } \\
\hline & & & & & & & $\begin{array}{l}\text { Function } \\
\text { score }\end{array}$ & $\begin{array}{l}\text { Knee } \\
\text { score }\end{array}$ & $\begin{array}{l}\text { Function } \\
\text { score }\end{array}$ & $\begin{array}{l}\text { Knee } \\
\text { score }\end{array}$ \\
\hline Duracon $^{\mathrm{a}}$ & $\begin{array}{l}\text { Multi-radius } \\
\text { Fixed-bearing } \\
\text { Cruciate retaining }\end{array}$ & 10 & $21(8.9)$ & $3 / 7$ & $68(10.9)$ & $29(3.7)$ & $\mathrm{x}$ & $\mathrm{x}$ & 88 (13) & $95(3)$ \\
\hline Triathlon $\mathrm{FB}^{\mathrm{a}}$ & $\begin{array}{l}\text { Single-radius } \\
\text { Fixed-bearing } \\
\text { Posterior-stabilized }\end{array}$ & 11 & $13(1.0)$ & $5 / 6$ & $66(9.1)$ & $30(6.2)$ & $52(18)$ & 43 (13) & $73(24)$ & $92(4)$ \\
\hline Triathlon $\mathrm{MB}^{\mathrm{a}}$ & $\begin{array}{l}\text { Single-radius } \\
\text { Mobile-bearing } \\
\text { Posterior-stabilized }\end{array}$ & 9 & $12(2.5)$ & $2 / 7$ & $63(9.6)$ & $31(7.5)$ & 48 (13) & $49(21)$ & $71(26)$ & $90(11)$ \\
\hline PFC-Sigma $^{\mathrm{b}}$ & $\begin{array}{l}\text { Multi-radius } \\
\text { Fixed-bearing } \\
\text { Posterior-stabilized }\end{array}$ & 8 & $5(1.0)$ & $4 / 4$ & $67(7.6)$ & $31(5.1)$ & $\mathrm{x}$ & $\mathrm{x}$ & $\mathrm{x}$ & $\mathrm{x}$ \\
\hline $\mathrm{NexGen}^{\mathrm{c}}$ & $\begin{array}{l}\text { Multi-radius } \\
\text { Mobile-bearing } \\
\text { Posterior-stabilized }\end{array}$ & 7 & $43(7.7)$ & $1 / 6$ & $67(8.2)$ & $30(3.1)$ & 43 (16) & $44(24)$ & 74 (30) & $84(18)$ \\
\hline $\mathrm{ROCC}^{\mathrm{d}}$ & $\begin{array}{l}\text { Multi-radius } \\
\text { Mobile-bearing } \\
\text { Cruciate sacrificing }\end{array}$ & 7 & $25(0.8)$ & $3 / 4$ & $63(10.9)$ & $29(5.6)$ & $50(26)$ & $47(12)$ & 79 (22) & $86(11)$ \\
\hline
\end{tabular}

Missing data are indicated with an ' $\mathrm{x}$ '

a Stryker, Kalamazoo, MI, USA

b DePuy Orthopaedics Inc., Warsaw, In, USA

c Zimmer Inc., Warsaw, In, USA

${ }^{\mathrm{d}}$ Biomet, Europe BV, Dordrecht, The Netherlands

significantly smaller (limited to $2.0^{\circ}$ ) than the mean range of axial rotations of the inserts of the Triathlon $\mathrm{MB}$ and ROCC groups $(P=0.010$ and $P=0.006$, respectively). There was no difference in axial insert rotation between the Triathlon and ROCC group. The mobile insert of the ROCC followed the motion of the femoral component until approximately $60^{\circ}$ of knee flexion. Beyond $60^{\circ}$ of knee flexion, 3 of 7 ROCC patients showed paradoxical axial rotations. The insert of the Triathlon patients followed the femoral component during the complete motion (maximum knee flexion during step-up was $80^{\circ}$ ), without showing paradoxical axial rotations.

\section{Pivot point of rotation}

Under the assumption that the inserts will follow the femoral component, a centrally located pivot point of axial rotation of the femoral component was expected. In all groups, except for the ROCC patients, the measured pivot point of axial rotation varied between a medial, central or lateral position. All the ROCC patients had a central point of rotation, except for one subject having a medial pivot point of axial rotation (Fig. 1).

Anterior-posterior translation of the contact points

The translations of the lateral condylar were essentially anterior throughout knee extension and translations of the medial condylar mainly posterior. The ROCC patients showed most reversed anterior-posterior motions. Six of seven patients had paradoxical motions at some point. One Triathlon MB patient had paradoxical motion, namely posterior translation during extension. The NexGen, Duracon, PFC-Sigma and Triathlon FB patients showed no paradoxical anterior-posterior motions. The Duracon group had larger translations of the medial condyle compared to the PFC-Sigma group $(P=0.021)$ and the NexGen group $(P=0.005)$ and of the lateral condyle compared to the Triathlon MB group $(P=0.015)$ and NexGen group $(P=0.003)$. Between the rest of the groups, there were no significant differences in anteriorposterior translation. 
Table 2 Mean and standard deviation of the range of knee flexion $\left({ }^{\circ}\right)$, axial rotation of the femoral component and the insert $\left(^{\circ}\right)$ and anteriorposterior (AP) translation $(\mathrm{mm})$ of the lateral and medial condyle during the step-up motion for each prosthetic group

\begin{tabular}{|c|c|c|c|c|c|}
\hline \multirow[t]{2}{*}{ Prosthesis } & \multirow[t]{2}{*}{ Knee flexion $\left({ }^{\circ}\right)$} & \multicolumn{2}{|l|}{ Axial rotation $\left(^{\circ}\right)$} & \multicolumn{2}{|c|}{ AP translation $(\mathrm{mm})$} \\
\hline & & Femoral component & Mobile insert & Medial condyle & Lateral condyle \\
\hline Duracon & $59.7(9.3)$ & $8.6(2.3)$ & - & $9.0(2.1)$ & $11.1(3.4)$ \\
\hline Triathlon FB & $60.3(5.4)$ & $8.3(2.7)$ & - & $6.6(1.5)$ & $7.1(1.8)$ \\
\hline Triathlon MB & $62.0(12.9)$ & $9.6(4.3)$ & $8.7(4.9)$ & $6.8(2.0)$ & $6.0(1.6)$ \\
\hline PFC-Sigma & $56.5(9.9)$ & $8.3(4.5)$ & - & $5.3(1.9)$ & $6.8(2.5)$ \\
\hline NexGen & $34.5(10.3)$ & $3.0(0.5)$ & $2.0(0.7)$ & $3.9(2.1)$ & $4.8(1.8)$ \\
\hline ROCC & $59.0(8.8)$ & $10.4(5.4)$ & $7.3(2.8)$ & $6.9(2.0)$ & $7.0(1.5)$ \\
\hline Levene's test & 0.83 n.s. & $3.80 P=0.006$ & $9.60 P=0.001$ & 0.31 n.s. & 1.74 n.s. \\
\hline $\begin{array}{l}\text { ANOVA Brown- } \\
\text { Forsythe }\end{array}$ & $\begin{array}{c}F(5,36.7)=8.38 \\
P=0.000\end{array}$ & $\begin{array}{l}F(5,25.1)=3.56 \\
P=0.014\end{array}$ & $\begin{array}{l}F(2,13.2)=9.11 \\
P=0.003\end{array}$ & $\begin{array}{l}F(5,40.7)=6.46 \\
P=0.000\end{array}$ & $\begin{array}{c}F(5,34.6)=8.55 \\
P=0.000\end{array}$ \\
\hline
\end{tabular}

Also, the results of the Levene's test and ANOVA are presented. There was a significant effect of prosthetic design on all outcome variables -: Fixed-bearing prosthesis; therefore, no 'mobile insert' data n.s. Not significant

\section{Discussion}

The aim of this study was to compare different total knee prostheses (multi-radius, single-radius, fixed-bearing, mobile-bearing, posterior-stabilized, cruciate retaining and cruciate sacrificing) to determine whether in vivo kinematics is consistently related to kinematics intended by the knee prosthesis design. According to several authors, in vivo knee kinematics after total knee arthroplasty is directly related to the constraints of the design of the prosthesis $[4,5,9]$. On the other hand, several studies found aberrant and highly unpredictable kinematics, and there was no distinction in clinical results and kinematics between different types of prostheses $[9,14,15,20,22-$ 24]. This study showed that despite kinematics being generally consistent with the kinematics intended by their design, there were no clear recognizable differences in in vivo kinematics between different design parameters or prostheses.

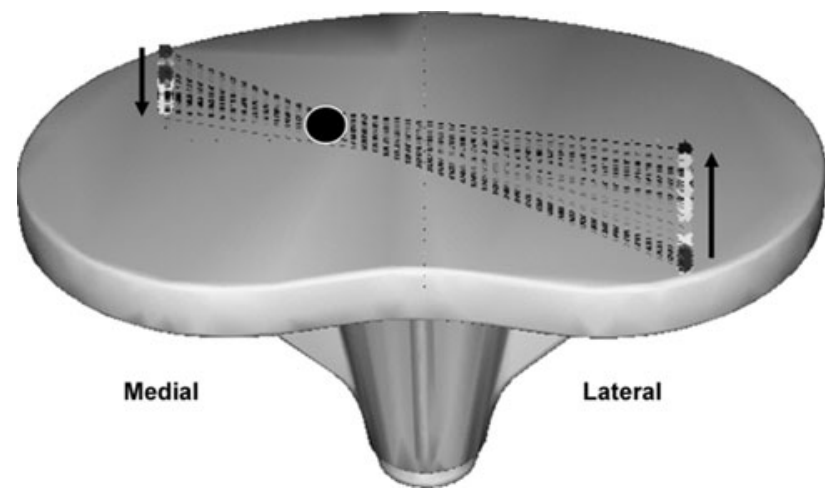

Fig. 1 Example of a medial pivot point of axial rotation. The medial condyle moves to posterior and the lateral condyle to anterior during knee extension
Patients with a cruciate sacrificing prosthesis (ROCC) cannot rely on the cruciate ligaments to provide stability. To compensate for this, the congruency of the insert is increased, providing more intrinsic stability between the insert and the femoral component. The increased congruency is also expected to lead to increased axial rotation of the mobile insert. This is supported by our fluoroscopic data, showing that the insert was following the femoral component until approximately $60^{\circ}$ of knee flexion. Beyond $60^{\circ}$ of knee flexion, diversion between the insert and the femoral component and reversed axial rotations occurred. Despite the lower congruency, the Triathlon MB group showed equal motion of the insert and femoral component during the whole range of flexion, without occurrence of reversed axial rotations. This suggests a more uniform motion in this group. A more uniform motion may reduce wear of the polyethylene, due to a reduction in shear forces at the liner interface $[6,19]$.

According to knee simulator studies, the reduction in sliding distance reduces the surface area of polyethylene being worn which in turn reduces wear $[18,19]$. The cruciate retaining group (Duracon) had the largest anteriorposterior motions, without revealing any reversed femoral tibial motion patterns. This is in accordance with the intended kinematics, keeping the posterior ligament to preserve normal rollback. The retained posterior ligament is assumed to increase joint stability compared to cruciate sacrificing total knees. This assumption is supported by the Duracon group having the highest post-operative KSS knee and function scores. Possibly, this patient group had also better function pre-operatively. Pre-operative scores and function are good indicators for post-operative scores and functions. Unfortunately, pre-operative scores were not quantified for these patients. 
All total knees showed comparable axial rotations of the femoral component with respect to the tibial component, except for the NexGen patients. The mobile inserts did not add additional mobility to the knee joint compared to the fixed-bearing groups. However, additional mobility was possibly not needed during the step-up motion performed. The inserts of two of the three mobile-bearing groups moved as predicted on theoretical grounds. The absence or reduced mobility in the NexGen patients makes this implant very similar to a fixed-bearing prosthesis. This absence or reduced mobility will also enhance wear of the polyethylene and could induce a higher incidence of loosening by transmitting larger forces to the bone-implant interface $[1,6,7,10,12,25,26]$.

In all three mobile-bearing prostheses used, the centrally located trunnion imposed a centrally located pivot point of rotation of the insert on top of the tibial plateau. Under the assumption that the inserts will follow the femoral component, a centrally located pivot point of axial rotation of the femoral component was expected. Only the ROCC patients had a measured central pivot point of axial rotation of the femoral component with respect to the tibial component. In the other two mobile-bearing groups, patients showed also medial and lateral pivot points of axial rotation. These deviant pivot points might be caused by low congruency between the insert and femoral component and by laxity of the surrounding ligaments [4]. However, no manifest laxity was seen in these patients.

A possible limitation of this and other multicenter studies, which could explain the variability in kinematics, is patient diversity (osteoarthritis and rheumatoid arthritis), pre-operative deformities, muscle adaptations and the different surgeons [3]. It is known that surgeons are still the biggest variable in outcome after total knee arthroplasty. Factors that play a major role in dysfunction of any knee and are determined by the surgeon are frontal plane malalignment, axial malrotation of the prosthesis, sagittal overstuffing of the knee, inappropriate level of joint space, inappropriate constraint or ligamentous imbalance and poor initial fixation of the implant [3, 8, 21].

Statistics showed that there was a significant effect of prosthetic design on all outcome parameters; however, post hoc tests showed that the NexGen group was responsible for $80 \%$ of the significant values. In this group, the range of knee flexion was much smaller, resulting in smaller anterior-posterior translations and rotations. It is not clear whether and why this patient group performed the step-up task differently.

This study showed that the in vivo kinematics of most included total knee prostheses were consistent with the kinematics intended by their design. However, some prostheses showed reversed or paradoxical kinematics in some parts of their functional range of motion. If the theoretical kinematics is not in accordance with the in vivo kinematics, the manufacture should optimize the new prosthetic design to prevent large scale polyethylene wear with subsequent prosthesis loosening. This is of importance because of the growing population of younger patients who will require an implant to function for at least two decades. Because of the high accuracy, it is recommended that fluoroscopy is used for evaluating the kinematics of new total knee prostheses before introducing the new knee worldwide on the market.

\section{Conclusion}

Despite kinematics being generally consistent with the kinematics intended by their design, there were no clear recognizable differences in in vivo kinematics between different design parameters or prostheses. Hence, the differences in design parameters or prostheses are not distinct enough to have an effect on clinical outcome of patients.

Acknowledgments This project was partly sponsored by European project DESSOS IST-2004-27252. The department of Orthopaedics (Leiden University Medical Center) received research funding for general use from Stryker Orthopaedics, USA. The sponsors had no role in the study design, data collection/analysis/interpretation, manuscript writing or the decision to submit the manuscript for publication. We would like to thank Dr. Eric Garling, department of Orthopedics of the Leiden University Medical Center, Professor Mark Taylor and Professor David Barrett from the University of Southampton and the orthopaedic surgeons of the Lange Land Hospital in Zoetermeer for their collaboration and support with patient inclusion.

Open Access This article is distributed under the terms of the Creative Commons Attribution Noncommercial License which permits any noncommercial use, distribution, and reproduction in any medium, provided the original author(s) and source are credited.

\section{References}

1. Andriacchi TP (1994) Dynamics of knee malalignment. Orthop Clin N Am 25:395-403

2. Andriacchi TP, Galante JO, Fermier RW (1982) The influence of total knee-replacement design on walking and stair-climbing. J Bone Joint Surg Am 64:1328-1335

3. Banks SA, Harman MK, Bellemans J, Hodge WA (2003) Making sense of knee arthroplasty kinematics: news you can use. J Bone Joint Surg Am 85-A(Suppl 4):64-72

4. Banks SA, Hodge WA (2004) 2003 Hap Paul Award Paper of the International Society for Technology in Arthroplasty. Design and activity dependence of kinematics in fixed and mobile-bearing knee arthroplasties. J Arthroplast 19:809-816

5. Banks SA, Hodge WA (2004) Implant design affects knee arthroplasty kinematics during stair-stepping. Clin Orthop Relat Res 426:187-193

6. Blunn GW, Joshi AB, Minns RJ, Lidgren L, Lilley P, Ryd L, Engelbrecht E, Walker PS (1997) Wear in retrieved condylar knee arthroplasties. A comparison of wear in different designs of 280 retrieved condylar knee prostheses. J Arthroplast 12:281-290 
7. Bottlang M, Erne OK, Lacatusu E, Sommers MB, Kessler O (2006) A mobile-bearing knee prosthesis can reduce strain at the proximal tibia. Clin Orthop Relat Res 447:105-111

8. Callaghan JJ (2001) Mobile-bearing knee replacement: clinical results: a review of the literature. Clin Orthop Relat Res 392: 221-225

9. Delport HP, Banks SA, De Schepper J, Bellemans J (2006) A kinematic comparison of fixed- and mobile-bearing knee replacements. J Bone Joint Surg Br 88:1016-1021

10. Dennis DA, Komistek RD, Mahfouz MR, Outten JT, Sharma A (2005) Mobile-bearing total knee arthroplasty: do the polyethylene bearings rotate? Clin Orthop Relat Res 440:88-95

11. Ewald FC (1989) The Knee Society total knee arthroplasty roentgenographic evaluation and scoring system. Clin Orthop Relat Res 248:9-12

12. Garling EH, Valstar ER, Nelissen RGHH (2005) Comparison of micromotion in mobile bearing and posterior stabilized total knee prostheses-A randomized RSA study of 40 knees followed for 2 years. Acta Orthop 76:353-361

13. Garling EH, Kaptein BL, Valstar ER, Nelissen RGHH (2007) Limited rotation of the mobile-bearing in a rotating platform total knee prosthesis. J Biomech 40(Suppl 1):S25-S30

14. Hall J, Copp SN, Adelson WS, D'Lima DD, Colwell CW Jr (2008) Extensor mechanism function in single-radius vs multiradius femoral components for total knee arthroplasty. J Arthroplast 23:216-219

15. Hilding MB, Lanshammar H, Ryd L (1996) Knee joint loading and tibial component loosening. RSA and gait analysis in 45 osteoarthritic patients before and after TKA. J Bone Joint Surg Br 78:66-73

16. Insall JN, Lachiewicz PF, Burstein AH (1982) The posterior stabilized condylar prosthesis: a modification of the total condylar design. Two to four-year clinical experience. J Bone Joint Surg Am 64:1317-1323

17. Kaptein BL, Valstar ER, Stoel BC, Rozing PM, Reiber JH (2003) A new model-based RSA method validated using CAD models and models from reversed engineering. J Biomech 36:873-882
18. McEwen HM, Barnett PI, Bell CJ, Farrar R, Auger DD, Stone MH, Fisher J (2005) The influence of design, materials and kinematics on the in vitro wear of total knee replacements. J Biomech 38:357-365

19. McEwen HM, Fisher J, Goldsmith AA, Auger DD, Hardaker C, Stone MH (2001) Wear of fixed bearing and rotating platform mobile bearing knees subjected to high levels of internal and external tibial rotation. J Mater Sci Mater Med 12:1049-1052

20. Pandit H, Ward T, Hollinghurst D, Beard DJ, Gill HS, Thomas NP, Murray DW (2005) Influence of surface geometry and the cam-post mechanism on the kinematics of total knee replacement. J Bone Joint Surg Br 87:940-945

21. Rousseau MA, Lazennec JY, Catonne Y (2008) Early mechanical failure in total knee arthroplasty. Int Orthop 32:53-56

22. Saari T, Tranberg R, Zugner R, Uvehammer J, Karrholm J (2005) Changed gait pattern in patients with total knee arthroplasty but minimal influence of tibial insert design: gait analysis during level walking in 39 TKR patients and 18 healthy controls. Acta Orthop 76:253-260

23. Saari T, Uvehammer J, Carlsson LV, Regner L, Karrholm J (2006) Influence of polyethylene constraint on tibial component fixation in total knee arthroplasty: follow-up report after 5 years. J Arthroplast 21:1032-1037

24. Snider MG, Macdonald SJ (2009) The influence of the posterior cruciate ligament and component design on joint line position after primary total knee arthroplasty. J Arthroplast 24:1093-1098

25. Stiehl JB, Dennis DA, Komistek RD, Keblish PA (1997) In vivo kinematic analysis of a mobile bearing total knee prosthesis. Clin Orthop Relat Res 345:60-66

26. Uvehammer J, Karrholm J, Carlsson L (2007) Influence of joint area design on tibial component migration: comparison among a fixed symmetrical, asymmetrical, and moveable bearing. J Knee Surg 20:20-26

27. Wang H, Simpson KJ, Ferrara MS, Chamnongkich S, Kinsey T, Mahoney OM (2006) Biomechanical differences exhibited during sit-to-stand between total knee arthroplasty designs of varying radii. J Arthroplast 21:1193-1199 